\title{
Estágio Supervisionado Regional: Visão do Aluno
}

\section{PALAVRAS-CHAVE \\ - Educação. \\ - Saúde. \\ - Internato Rural.}

\section{KEYWORDS}

- Education.

- Health.

- Rural Internship.

Recebido em: 03/07/2010

Aprovado em: 08/09/2011

REVISTA BRASILEIRA DE EDUCAÇÃO MÉDICA

\author{
Regional Supervised Internship: \\ the Student's View
}

\author{
Renata Vidal Cardoso Gardenal \\ Ana Maria Campos Marques \\ Lílian Bianca Martello \\ Lucylea Pompeu Muller Braga \\ Marcos Marinelli Bonilha \\ Odilei Braga \\ Leandro Almeida Assunção
}

\section{RESUMO}

O curso de Medicina da Uniderp/Anhanguera busca graduar um médico apto a desenvolver ações condizentes com os princípios do Sistema Único de Saúde (SUS). Para isto, é necessário que o aluno realize as atividades práticas do quinto e sexto anos nos três níveis de atenção à saúde e em diferentes cenários do Estado do Mato Grosso do Sul. Para alcançar tais objetivos, foi idealizado o Estágio Supervisionado Regional (ESR), em que os alunos do sexto ano desenvolvem atividades práticas em alguns municípios do Estado. Semanalmente, via Nead, os alunos enviam relatório em que descrevem as atividades, demonstram seus conhecimentos teóricos e práticos, fazem autoavaliação conforme o Plano de Ensino, organizam as atividades teóricas e tecem críticas sobre o funcionamento do estágio. Estes relatórios são arquivados no Nead. Foram buscados os conteúdos referentes aos depoimentos e críticas, para fazer um relato da visão do aluno nesse momento de aprendizado extramuros da academia.

\section{ABSTRACT}

The Uniderp/Anhanguera Medicine Course aims to graduate physicians capable of working in line with the principles of the Unified Health System (SUS). In order to achieve this, fifth and sixth year students partake in practical activities at all three levels of health care and in different settings in Mato Grosso do Sul. The Regional Supervised Internship was designed to allow sixth year students this work experience opportunity in some towns in the State. The students send weekly reports, via the Nead system, in which they describe their activities, demonstrate their theoretical and practical knowledge, present self-assessments as per the Learning Plan, organise theoretical activities and develop critical reviews of the internship. These reports are filed on the Nead system. Searches were made for content relative to such accounts and reviews in order to construct the student's vision of this learning opportunity beyond the university walls. 


\section{INTRODUÇÃO}

O movimento de reformulação do ensino superior brasileiro proposto pelos ministérios da Educação e da Saúde visa adaptar a formação dos novos profissionais de saúde às novas necessidades do País, em conformidade com a Constituição de 1988 e segundo as diretrizes do Sistema Único de Saúde (SUS). Este processo tem sido documentado e divulgado com o objetivo de subsidiar a discussão e as mudanças nos cursos que ainda não implantaram as diretrizes curriculares em seus projetos pedagógicos ${ }^{1,2}$. Diante dessas transformações, é crescente a demanda pela intensificação dos debates sobre como estruturar o internato do curso médico ${ }^{3}$.

Na década de 1950, iniciaram-se programas destinados à prática pré-profissional supervisionada no sexto ano, como complemento ao conteúdo predominantemente teórico dos anos anteriores. Entretanto, o Internato Médico foi oficializado apenas em 1969, quando se normatizou a obrigatoriedade de um período prático com características especiais no final da formação acadêmica dos cursos de graduação em Medicina ${ }^{4}$.

Segundo o Ministério da Educação e Cultura (MEC) ${ }^{5}$, o internato ou estágio curricular é o "último ciclo do curso de graduação em Medicina, livre de disciplinas acadêmicas, durante o qual o estudante deve receber treinamento intensivo, contínuo, sob supervisão docente, em instituição de saúde vinculada, ou não, à escola médica".

É preciso construir conhecimentos sobre novas propostas de Internato Médico que venham ao encontro da formação de um profissional ético-crítico e reflexivo, com capacidade de atender às necessidades da população. Assim, o SUS se faz presente como ferramenta essencial por intermédio das Equipes da Estratégia de Saúde da Família (ESF), das Equipes de Saúde da Família Indígena (Esfi) do Distrito Sanitário Especial Indígena da Fundação Nacional de Saúde do Ministério da Saúde (DSEI/Funasa-MS) e dos hospitais regionais que promovem a atenção terciária na região. Para tanto, é necessário que o aluno realize suas atividades práticas do Estágio Supervisionado (ES) nos três níveis de atenção à saúde e que essas atividades contemplem as diferentes populações e culturas de cada Estado.

Em 1978, foi implantado um dos mais antigos projetos deste tipo de atividade de extensão no Estado de Minas Gerais. Hoje com 31 anos, tem contribuído para a formação de mais de 7 mil médicos e executa ações assistenciais, de prevenção e promoção da saúde, contribuindo para a evolução histórica das políticas sociais e de saúde do referido Estado ${ }^{6}$.

O curso de Medicina da Universidade Anhanguera/Uniderp, ao buscar se adaptar às novas necessidades e realidades, baseou seu projeto pedagógico no objetivo de graduar um médico apto a desenvolver ações de promoção, prevenção, proteção e reabilitação, além de ser capaz de tomar decisões com base na eficácia e custo-efetividade, além de se adequar à realidade locorregional. $\mathrm{O}$ aluno desenvolve suas atividades práticas do quinto e sexto anos nos três níveis de atenção à saúde, a qual busca contemplar as diferentes populações e culturas do Estado do Mato Grosso do Sul.

Para alcançar tais objetivos, foi idealizado o Estágio Supervisionado Regional (ESR), em que os alunos do sexto ano desenvolvem habilidades técnicas e de raciocínio clínico em alguns municípios do interior do Estado, onde participam de atividades no âmbito das equipes de ESF urbana e indígena, nos assentamentos e hospitais regionais de baixa e média complexidade. O estágio tem ainda como objetivo fomentar no aluno a capacidade de mobilizar e combinar, diante de problemas específicos, um conjunto de conhecimentos especializados e saberes, habilidades e atitudes e, assim, oferecer uma aprendizagem significativa para qualificar a atenção prestada a esta população.

A avaliação do estágio é feita a partir de uma composição de notas: uma avaliação formativa, com peso 7, obtida a partir da avaliação do preceptor local, das supervisões semanais, da descrição do relatório semanal e da apresentação de um tema escolhido pelos alunos sobre a experiência local em forma de seminário; e uma avaliação somativa, com peso 3 , composta de uma prova que abrange todo o conteúdo contido no plano de ensino para o semestre.

Os alunos estão distribuídos em grupos de dois a oito, com rodízios a cada dez semanas, de acordo com as vagas oferecidas pelos municípios. Semanalmente, via internet, eles enviam um relatório das atividades, utilizando uma ferramenta disponibilizada pela universidade (Nead). Nesse relatório, eles descrevem as atividades desenvolvidas, demonstrando conhecimentos teóricos e práticos, fazem uma análise crítica das mesmas e uma autoavaliação com o propósito de verificar se estão atingindo os objetivos propostos pelo Plano de Ensino, organizam as atividades de estudos da semana seguinte e tecem críticas sobre o funcionamento do estágio.

A avaliação crítica das atividades desenvolvidas e do próprio estágio tem fornecido dados importantes, muitas vezes decisivos no estabelecimento de estratégias e rumos para a continuidade do estágio. Como estes relatórios permanecem arquivados neste ambiente virtual desde a primeira turma de alunos, resolveu-se buscar os conteúdos referentes aos depoimentos e críticas contidos nestes relatórios para fazer um relato da visão do aluno nesse momento de aprendizado extramuros da academia. 


\section{METODOLOGIA}

Relato da experiência do internato do curso de Medicina da Universidade Anhanguera/Uniderp por meio da extração aleatória de trechos dos depoimentos e críticas contidos nos relatórios enviados pelos alunos no período de 2005 a 2009. A partir destes textos, foi realizada uma análise sistemática dos depoimentos e posterior extrapolação da visão deles em forma de resumo.

\section{RESULTADOS}

Segundo a coletânea de depoimentos, observamos que, mesmo diante da especificidade de vida desta fase em que se encontram - cheios de dúvidas e incertezas em relação ao futuro profissional -, os alunos demonstram, em sua maioria, maturidade e respeito por seu trabalho e pelo trabalho dos profissionais que acompanham.

Segundo os depoimentos e críticas analisados, todos os alunos que cumpriram o estágio afirmam que esse tempo foi valioso para consolidar seu nível de aprendizado e sua capacidade de resolver problemas e de se adaptar às situações novas. Dizem que retornam mais "maduros" e mais "seguros" para o enfretamento das responsabilidades profissionais futuras, além de se sentirem gratos pela oportunidade que o curso oferece e pela excelente recepção da população e das autoridades e profissionais dos municípios envolvidos.

Como exemplo, transcrevemos um depoimento de um acadêmico que se encontrava no estágio nas aldeias indígenas do município de Aquidauana e suas reflexões sobre o trabalho em equipe e com populações especiais: “Com este estágio tivemos uma visão de como funciona o atendimento dado aos povos indígenas pela Funasa; pudemos perceber que as dificuldades são muitas, mas isso é contornado pela boa vontade e dedicação de seus funcionários".

Outros pontos importantes analisados e inegavelmente construídos neste estágio são a responsabilidade, o trabalho em equipe, autonomia e tomada de decisão. Estes atributos também estavam bem explícitos nos relatórios: "Através do acompanhamento de nossos colegas que futuramente frequentarão as aldeias indígenas de Aquidauana, e darão continuidade a este trabalho a fim de promover a erradicação dos quadros de desnutrição indígena nas aldeias de Aquidauana, Taunay e Nioaque - favorecendo tanto as comunidades estudadas, como também a satisfação pessoal dos que estiverem envolvidos neste trabalho e o desenvolvimento de trabalhos científicos relacionados à desnutrição nesta região"; "A maior habilidade que aprendi neste internato foi a tomada de decisões no momento correto e a de resolver em equipe os proble- mas dos pacientes para um melhor atendimento e evolução destes".

Existem pontos negativos, na maioria das vezes relacionados a questões de infraestrutura, como alojamento e alimentação, que fogem ao escopo deste trabalho.

\section{CONSIDERAÇÕES FINAIS}

A oportunidade de desenvolver habilidades técnicas e de raciocínio em um estágio nos municípios interioranos, seja na atenção primária, seja num hospital de baixa ou média complexidade e diante de realidades muitas vezes desprivilegiadas, coloca o discente do sexto ano de Medicina frente a dificuldades de atendimento semelhantes às da maioria dos municípios brasileiros. Neste cenário desfavorável em relação às tecnologias ditas pesadas, impõe-se a prática do método clínico, a tecnologia leve e humana, além das intervenções médicas mais comuns no exercício da profissão.

Assim, embora se trate de um relato de experiência de uma fonte de dados secundária, passível de vieses, pode-se concluir que o ESR permite formar um profissional capaz de prestar assistência integral à saúde, atento aos determinantes sociais, culturais, psicológicos e antropológicos do processo de saúde-doença de comunidades especiais. Esse fato é demonstrado pelos ex-alunos, hoje médicos no exercício da profissão, que elegeram para iniciar sua vida profissional os municípios onde estagiaram.

\section{REFERÊNCIAS}

1. Lima VV, Komatsu RS, Padilha RQ. Desafios ao desenvolvimento de um currículo inovador: a experiência da Faculdade de Medicina de Marília. Interface Comum Saúde Educ. 2003;7(12):175-84.

2. Cyrino EG, Rizzato ABP. Contribuição à mudança curricular na graduação da Faculdade de Medicina de Botucatu. Rev Bras Saúde Mater Infant. 2004;4(1):59-69.

3. Chaves ITS, Grosseman, S. O Internato Médico e suas perspectivas. Estudo de casos com educadores e educandos. Rio de Janeiro. Rev Bras Educ Med. 2007; 31(3):212-22.

4. Associação Brasileira de Educação Médica. O internato nas escolas médicas brasileiras. Rio de Janeiro: ABEM; 1969.

5. Brasil. Ministério da Educação. Secretaria de Ensino Superior. Manual do internato. Brasília: MEC; 1984.

6. Polignano MV, Melo EM, Nascimento LE, Santana AMP, Rodrigues Júnior IA. Internato rural da Faculdade de Medicina: 25 anos de integração docente-assistencial. In: Anais do $2^{\circ}$ Congresso Brasileiro de Extensão Universitária. Set 2004, Belo Horizonte, MG. 


\section{CONTRIBUIÇÃO DOS AUTORES}

Todos os autores participaram da redação e revisão final do artigo. Renata Vidal C. Gardenal, Ana Maria de Campos Marques e Leandro Almeida Assunção realizaram também a tabulação de dados.

\section{CONFLITO DE INTERESSES}

Declarou não haver.

\section{ENDEREÇO PARA CORRESPONDÊNCIA}

Leandro Almeida Assunção

Universidade para o Desenvolvimento do Estado e da Região do Pantanal.

Rua Ceará, 333 - Bairro Miguel Couto - Campo Grande 79003-010 - Cx Postal: 2153 MS

E-mail: 1.assuncao@yahoo.com.br 